\title{
Olivier Odaert, Saint-Exupéry écrivain
}

\section{Elena Ravera}

\section{OpenEdition}

\section{Journals}

\section{Edizione digitale}

URL: https://journals.openedition.org/studifrancesi/21642

DOI: 10.4000/studifrancesi.21642

ISSN: 2421-5856

\section{Editore}

Rosenberg \& Sellier

\section{Edizione cartacea}

Data di pubblicazione: 1 décembre 2019

Paginazione: 604-605

ISSN: 0039-2944

\section{Notizia bibliografica digitale}

Elena Ravera, «Olivier Odaert, Saint-Exupéry écrivain», Studi Francesi [Online], 189 (LXIII | III) | 2019,

online dal 01 mars 2020, consultato il 11 novembre 2021. URL: http://journals.openedition.org/ studifrancesi/21642 ; DOI: https://doi.org/10.4000/studifrancesi.21642

Questo documento è stato generato automaticamente il 11 novembre 2021.

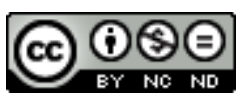

Studi Francesi è distribuita con Licenza Creative Commons Attribuzione - Non commerciale - Non opere derivate 4.0 Internazionale. 


\title{
Olivier Odaert, Saint-Exupéry écrivain
}

\author{
Elena Ravera
}

\section{NOTIZIA}

Olivier Odaert, Saint-Exupéry écrivain, Louvain-la-Neuve, Presses Universitaires de Louvain, 2018, 214 pp.

1 Professore di letteratura e filosofia all'École Supérieure des Arts di Tournai, nel suo ultimo saggio Olivier Odaert propone un'analisi generale del lavoro di quello che è considerato uno degli scrittori più letti e amati al mondo, ma la cui fama di aviatore ne ha spesso ingiustamente messo in ombra la fruttuosa e prolifica carriera letteraria. Come sottolinea lo stesso Odaert nell'introduzione del libro (pp. 5-24), l'obiettivo del suo studio è di intraprendere, instaurando un dialogo tra i testi di Saint-Exupéry e le realtà storiche, sociali e culturali che li concernono, un atto di rivalutazione del ruolo occupato dall'autore lionese nella storia delle rappresentazioni e delle idee, al fine di riassegnargli una più adeguata posizione nell'universo della letteratura.

2 La prima parte, intitolata «Initiations» (pp. 25-103), si struttura in quattro capitoli, nei quali viene affrontato un esame metodico e progressivo della poetica saint-exuperiana e della sua influenza sull'immaginario collettivo, con un'attenzione particolare per uno dei leitmotif della sua opera: l'aviazione. Il primo, infatti, si dedica alla ricostruzione di un'autentica «Poétique de l'aviation» (pp. 27-37) nella storia della letteratura francese e non solo, individuando i possibili modelli e precursori di Saint-Exupéry, mentre il secondo ne mette in evidenza i movimenti di «Régressions» (pp.39-60) rispetto agli aspetti contenutistici e formali della letteratura aeronautica della sua epoca, mostrando come, a partire da Courrier Sud, i toni intimisti e le atmosfere notturne adottati dallo scrittore-aviatore lo discostino, in realtà, dalla maggior parte delle rappresentazioni dedicate alla tematica dell'aviazione a lui contemporanee, di carattere generalmente più eroico e solare. Nel terzo capitolo, dal titolo «Renaissances» (pp. 61-82), Odaert si sofferma invece su una nuova tipologia del romanzo di aviazione fondata sul romanzo iniziatico, per mostrare infine, nel quarto e ultimo capitolo di 
questa prima sezione, in che modo le strutture narrative adottate da Saint-Exupéry si prestino ad essere interpretate come un ritorno alle «Enfances» (pp. 83-103) e alle origini del mito letterario del piccolo principe.

3 Se la prima parte del saggio è dunque concepita come una presentazione globale dell'opera saint-exuperiana e del contesto storico e letterario in seno al quale si inserisce, la seconda ne studia le «Filiations» (pp. 105-184), ovvero la partecipazione e l'influenza nell'ambito della storia delle idee, mettendo in luce come la poetica dello scrittore abbia alimentato, attraverso la sua ascendenza sull'immaginario collettivo, la diffusione di un'assiologia novatrice strettamente legata a quegli sconvolgimenti di tipo etico e morale di cui il xx secolo è stato protagonista. Il primo capitolo di questa seconda, densa sezione propone un confronto tra la «Poétique de la valeur» (pp. 107-117) di Saint-Exupéry e di Nietzsche, giacché entrambi gli autori mettono in atto, nei loro testi, un rovesciamento radicale delle rappresentazioni platoniche e giudaicocristiane. Lo studio dell'inversione dei valori di cui si nutrono la poetica e la narrativa saint-exuperiane è invece al centro del secondo, che ne descrive, appunto, l'«Héroïsme de la relation» (pp. 119-135), tematica che verrà poi ampliata e approfondita nel terzo, dove Odaert instaura un dialogo tra la filosofia morale di Sartre e Arendt e la «Morale de la responsabilité» (pp. 137-169) adottata dallo scrittore lionese. Infine, il quarto e ultimo capitolo si focalizza sulle implicazioni etiche collettive alimentate dai suoi testi, delineando una «Politique de la réconcilitation» (pp. 171-184).

4 Nella conclusione del volume, Odaert ripropone quindi l'invito a discostarsi momentaneamente dal profilo dell'aviatore e di «Toucher terre» (pp. 185-191), al fine di rivalutare, come insiste anche nell'epilogo, «Saint-Exupéry et son double» (pp. 193-202): solo così - suggerisce l'autore -, dietro al mito eroico del pilota di aerei, il lettore potrà scorgere lo spessore umano dello scrittore e, acconsentendogli di confondersi con le pagine della sua opera, riscoprire la bellezza del suo lavoro letterario. 